Rachel Zuanon> Lara D. Balaminutti>> Mateus de Oliveira $\gg>$ Vanessa Zaccarias Filipe Mattos de Salles

\footnotetext{
Artista midiática e designer. Professora e pesquisadora do DAP e do PPG-AV (IA-UNICAMP) e do PPG-ATC (FEC-UNICAMP). Cofundadora e co-coordenadora da DASMind-UNICAMP [Design, Art, Space and Mind: Transdisciplinary Cooperation Network in Research and Innovation]. Com prêmios nacionais e internacionais, desde 1998, dedica sua pesquisa e producões à cooperação Neurociência e Processos Criativos e Projetuais. rzuanon@unicamp.br
}

ORCID ID: 0000-0002-7917-9917

$\gg$ Mestranda no Programa de PósGraduação em Artes Visuais do Instituto de Artes, da Universidade Estadual de Campinas (PPG-AV IA-UNICAMP). Graduada em Artes Visuais (Bacharelado e Licenciatura) pelo IA-UNICAMP. Bolsista do "Programa de Formação Didático-Pedagógica para Cursos de Modalidade a Distância", da UNIVESP. Membro da rede de cooperação transdisciplinar em pesquisa e inovação DASMind-UNICAMP. 1171615@dac.unicamp.br

ORCID ID: 0000-0002-7968-4518

$\gg$ Graduando em Arquitetura e Urbanismo na Faculdade de Engenharia Civil Arquitetura e Urbanismo, da Universidade Estadual de Campinas (FECUNICAMP). Bolsista PIBIC-CNPq. Membro da rede de cooperação transdisciplinar em pesquisa e inovação DASMind-UNICAMP. m222039@dac.unicamp.br

\section{Desenho Sensorial: o método SEE BEYOND aplicado ao ensino-aprendizagem dos elementos compositivos 'contraste, equilíbrio e peso' no desenho artístico}

\section{Resumo}

Este artigo discorre sobre a abordagem do Desenho Sensorial, aplicada ao ensino- aprendizagem do desenho artístico. O Desenho Sensorial é subsidiado pelo método SEE BEYOND, o qual elabora e aplica recursos didático-pedagógicos e didático-andragógicos direcionados a estudantes com e sem deficiência visual, a partir de estudos da neurociência cognitivo-comportamental e da neuroeducação. Os resultados, as discussões e as contribuições aqui compartilhados referem-se especificamente ao tema 'Contraste, equilíbrio e peso', ministrado no primeiro semestre do ano de 2019, e que integra o conteúdo programático da disciplina Desenho Artístico I (AP104), pertencente à matriz curricular do curso de Artes Visuais, da Universidade Estadual de Campinas (UNICAMP).

Palavras-chave: Artes Visuais. Neurociências. Neuroeducação. Desenho Sensorial. SEE BEYOND. Desenho Artístico. 
Rachel Zuanon

Lara D. Balaminutti

Mateus de Oliveira

Vanessa Zaccarias ${ }^{>}$

Filipe Mattos de Salles ${ }^{>}$

\section{Sensory Drawing: the SEE BEYOND method applied to the teaching-learning of the visual compositional elements 'contrast, balance and weight' in artistic design}

\begin{abstract}
This article discusses the Sensory Drawing approach, applied to the teaching-learning of artistic design. Sensory Drawing is subsidized by the SEE BEYOND method, which elaborates and applies didacticpedagogical and didactic-andragogic resources directed to students with and without visual impairment, based on studies of cognitivebehavioral neuroscience and neuroeducation. The results, discussions and contributions shared here refer specifically to the theme 'Contrast, balance and weight', taught in the first half of 2019, and which integrates the syllabus of the discipline Artistic Drawing I (AP104), belonging to the curricular matrix of the Visual Arts course at the State University of Campinas (UNICAMP).
\end{abstract}

Keywords: Visual Arts. Neurosciences. Neuroeducation. Sensorial Drawing. SEE BEYOND. Artistic Drawing.

fmsalles@unicamp.br 


\section{Introdução}

O desenho ou o ato de desenhar é uma atividade significativa ao desenvolvimento humano. Como forma e meio de expressão, o desenho permeia a história da humanidade (DUARTE, 2004). Como representação, os desenhos trazem consigo a concepção de registro das imagens que sensibilizam o ser humano. Imagens que habitam suas mentes, sejam elas frutos da sua imaginação ou do seu entorno. E como meio de comunicação, o desenho se apresenta como uma das maneiras pelas quais o indivíduo explicita suas narrativas. O ser humano conta estórias e a sua própria história, por meio de símbolos ou sinais que o represente (CARDEAL, 2009).

Já como prática projetual, o desenho se coloca como base para outros meios de expressão, nos mais distintos suportes e a partir de diversos instrumentos, como a pintura, a escultura, a gravura, a arquitetura, o design, dentre tantos outros. Ainda, o desenho integra importantes invenções, como visualização de estudos científicos em astronomia, física, anatomia, entre muitos outros. Nesta trajetória, o desenho mostra-se crucial à construção do conhecimento e à explicitação de conceitos, em cada uma dessas áreas, até então abstratos à mente humana (ALMEIDA, 2009; JULIAZ, ALMEIDA, 2010).

Importante, assim, perceber o desenho como algo intrínseco aos mecanismos mentais do ser humano, e atuante na sua evolução sensório-motora, cognitiva e comportamental. Pelos traços, linhas, texturas, cores, elementos compositivos do desenho, o indivíduo também elabora a sua afetividade e materializa as emoções, sensações e pensamentos, inicialmente vivenciados em sua mente e experienciados no seu corpo, como um todo. A partir deste entendimento, a aproximação entre os campos do desenho e da neurociência cognitivo-comportamental mostra-se natural. Enquanto a neurociência cognitiva trata das capacidades mentais mais complexas, geralmente típicas do ser humano, como a linguagem, a memória, a autoconsciência etc., a neurociência comportamental dedica-se a estudar as estruturas neurais que produzem comportamentos e outros fenômenos psicológicos, como a emoção (LENT, 2008). Assim, ao investigar a cognição e o comportamento a partir da observação das propriedades físicas e neuropsicofisiológicas do cérebro (VARELA et al., 2003), a neurociência traz contributos relevantes à criação e à prática do 
desenho, bem como à sua interpretação, enquanto materialização destes processos orgânicos. Tais contribuições se ampliam sobremaneira quando também associadas às práticas pedagógicas e andragógicas de ensino-aprendizagem, o que configura o campo da neuroeducação.

A neuroeducação se dedica a aprimorar o processo de formação do educador, assim como o processo de aprendizagem do estudante. Mais que aplicar os conceitos da neurociência cognitivo-comportamental no ensino, a neuroeducação se interessa em identificar condições neuropsicofisiológicas, e seus respectivos mecanismos cerebrais, que atuam nas emoções, nos sentimentos, na curiosidade, na atenção, na consolidação e na evocação dos conhecimentos adquiridos e, portanto, na aprendizagem. Além disso, ela se debruça na detecção de déficits, com o intuito de prevenir, reduzir e mitigar as consequências de práticas metodológicas e ambientes educacionais inadequados ao ensino-aprendizagem (MORA, 2013). Em síntese, a neuroeducação assume a responsabilidade de investigar o processo de aprendizagem, e de explicar aos educadores os níveis de complexidade neuronal envolvidos neste processo, e as decorrentes respostas cognitivo-comportamentais passíveis de ocorrer e/ou ser identificadas nos estudantes (BRANDÃO E CALIATTO, 2019). Instrumentalizados com os referenciais da neuroeducação, os docentes passam a adotar critérios aderentes a estes referenciais para elaborar seus métodos de ensino, direcionar os estímulos e as atividades em sala de aula, e orientar suas práticas avaliativas, com vistas a resultados didático-pedagógicos e didático-andragógicos mais alinhados e consistentes às necessidades do organismo humano.

No âmbito da formação de nível superior em artes e em design, a cooperação entre os campos do desenho e da neuroeducação, para além de instrumentalizar os educadores às melhores práticas pedagógicas nos referidos contextos, também representa profícua contribuição aos artistas e aos designers em formação, especialmente no que concerne ao alcance de uma expressão poético-artística e projetual autoral. Ou seja, ao compreender os mecanismos que estão na base da cognição e do comportamento humano, o docente responsável pelos processos de ensino-aprendizagem do desenho passa a entender a inadequação de replicar modelos preestabelecidos e de condicionar seus estudantes a réplicas de padrões, frente às características, às necessidades e às urgências individuais e coletivas dos aprendizes no cenário contemporâneo. E, assim, consegue perceber a importância de investigar caminhos e estratégias metodológicas que dialoguem com os mecanismos cognitivo e comportamental dos estudantes, de modo que a assimilação, a consolidação e a evocação do conhecimento sejam potencializadas ao longo de todo esse processo, e favoreça a construção de um percurso poético-artístico e projetual autoral.

A esta perspectiva se alinha o método SEE BEYOND, que valoriza a concepção e a aplicação de instrumentos didático-pedagógicos, didático-andragógicos, e de atividades teórico-práticas, todos direcionados à estimulação somatossensorial e sensório-motora dos estudantes, seja no âmbito do ensino-aprendizagem de 
metodologia projetual em design, ou de desenho artístico. Ao estimular cada indivíduo na sua dimensão individual e coletiva, o método SEE BEYOND almeja que o estudante retenha a informação obtida em aula por intermédio dos estímulos somatossensoriais e sensório-motores e, a partir deles, processe as imagens mentais "(...) visões, sons, sensações táteis, cheiros, gostos, dores, prazeres e coisas do gênero - imagens, em suma" (DAMÁSIO, 2011, p. 95-6), que posteriormente serão materializadas nas suas práticas autorais, sejam elas projetuais e/ou poético-artísticas.

Neste artigo, é apresentada a abordagem do Desenho Sensorial, a qual é subsidiada pelo método SEE BEYOND e seus princípios. Os resultados, as discussões e as contribuições aqui compartilhados referem-se à esta abordagem aplicada especificamente ao tema 'Contraste, equilíbrio e peso', ministrado no primeiro semestre do ano de 2019, e que integra o conteúdo programático da disciplina Desenho Artístico I (AP104), pertencente à matriz curricular do curso de Artes Visuais, da Universidade Estadual de Campinas (UNICAMP).

\section{See beyond}

O método SEE BEYOND foi estruturado inicialmente para o ensino de metodologia projetual no campo do Design. Por meio dele, são elaborados e aplicados recursos didáticos, como instrumentos didático-pedagógicos, didático-andragógicos e atividades teórico-práticas, direcionados à estimulação somatossensorial e sensório-motora de estudantes com e sem deficiência visual. Este método é constituído por três módulos: Fundamentação (LIMA JR., ZUANON, 2017); Potencialização (LIMA JR., ZUANON, 2018a); e Materialização (LIMA JR., ZUANON, 2019). E por dez princípios norteadores: [A] Conexão à natureza cerebral; [B] Regulação homeostática; [C] Transversalidades do método; [D] Percepção sensório-motora; [E] Abstração multidimensional; [F] Dinâmicas perceptivo-emocionais; [G] Fluxos motivacionais; [H] Conexão ao cérebro individual; [I] Conexão ao cérebro social; [J] Posicionamento crítico reflexivo (LIMA JR., ZUANON, 2019). Tanto seus módulos, quanto seus princípios ampliam a estrutura das metodologias projetuais tradicionalmente aplicadas em cursos de formação superior em Design no Brasil, ao incorporar estudos da neurociência cognitivo-comportamental [COSENZA, 2011; CARTER, 2003; DAMÁSIO, 2004; DAMÁSIO, 2011; DAMÁSIO, 2012; DREW ET AL, 2011; MARTIN, 2013; MATURANA, VARELA, 2010; SACKS, 2010; NICOLELIS, 2011; FEUERSTEIN, 2014] e da neuroeducação [BALLESTERO-ALVAREZ, 2003; TABACOW, 2015; TOKUHAMA-ESPINOSA, 2008] no seu planejamento pedagógico e andragógico (ZUANON, LIMA JÚNIOR, 2018b, 2019).

Em primeira instância, SEE BEYOND é validado junto a estudantes com deficiência visual, sem experiência ou contato prévio com conteúdos/referências acadêmicas relativos ao campo do Design. Posteriormente, sua validação é realizada junto a estudantes videntes. Este método, ao mesmo tempo que inclui o deficiente visual no contexto da formação de nível superior em Design, também amplia os estímulos experienciados 
pelos estudantes videntes; expande a percepção dos elementos projetuais necessários ao desenvolvimento de projetos em design; e potencializa o processo de ensino-aprendizagem de estudantes, com ou sem deficiência visual (LIMA JR., ZUANON, 2018b) .

Dada sua natureza transdisciplinar, o método SEE BEYOND não se restringe ao seu campo de origem, no caso o Design. Contrário disso, sua aplicação se estende às demais áreas do conhecimento que envolvem o pensar e o fazer projetual, como as Artes Visuais. No ano de 2019, a aplicação do método SEE BEYOND é expandida a outras matrizes curriculares do ensino superior, especificamente ao ensino-aprendizagem do Desenho Artístico. Isso tem como objetivo impulsionar o desenvolvimento e o alcance de uma expressividade artística autoral, no contexto da formação de nível superior de artistas visuais contemporâneos. Neste âmbito, são trabalhados conteúdos expositivos, com referências teóricas, projetuais e poéticas do campo das Artes, e realizadas dinâmicas práticas, que empregam estímulos somatossensoriais e sensório-motores. Nestas dinâmicas sensoriais, o sentido da visão dos estudantes é anulado, para que os demais sentidos (tátil, olfativo, auditivo e gustativo) sejam potencializados. A ausência da visão durante as dinâmicas sensoriais amplia a participação e a contribuição dos demais sentidos no processo de percepção. Essa ação além de expandir o potencial perceptivo dos estudantes, favorece sobremaneira o processo de assimilação, consolidação e evocação do conhecimento, seja em circunstância imediata ou futura. A partir da perspectiva e da aplicação do método SEE BEYOND, propomos a abordagem do Desenho Sensorial para o ensino-aprendizagem dos elementos compositivos do desenho artístico, como discorremos na sequência.

\section{Desenho sensorial}

\subsection{Estímulos Somatossensoriais e Sensório-Motores}

Por meio da abordagem do Desenho Sensorial (subsidiada pelo método SEE BEYOND), o tema 'contraste, equilíbrio e peso' é desenvolvido no contexto da disciplina Desenho Artístico I (AP104), ministrada no Instituto de Artes, da Universidade Estadual de Campinas [UNICAMP]. 'Contraste, equilíbrio e peso' compreende o quinto eixo temático trabalhado com os estudantes desta disciplina, e ocupa a décima aula do semestre. Os temas abordados nas aulas anteriores são: (1) linha; (2) contorno e preenchimento; (3) figura e fundo; e (4) movimento e ritmo, portanto, neste momento da disciplina os alunos já têm familiaridade com as dinâmicas sensoriais e com a prática do desenho 'cego'. Com duração total de quatro horas, a primeira hora de aula é dedicada à apresentação de referências visuais/audiovisuais e teóricas, acerca do tema proposto, e as demais à prática das dinâmicas sensoriais. Importante destacar que estas dinâmicas sempre são realizadas com as luzes apagadas, empregam um momento inicial de concentração meditativa, assim como estimulações somatossensoriais e sensório-motoras ao longo do seu processo. Neste âmbito, a visão dos estudantes é anulada com o uso de tapa olhos, a fim 
de potencializar os demais sentidos e agregar outras percepções aos temas desenvolvidos no conteúdo programático. Ainda, é facultado aos estudantes desenvolverem suas composições visuais com ou sem o tapa olhos.

$\mathrm{Na}$ dinâmica sensorial realizada em 03 de junho de 2019, os alunos são estimulados a perceber a presença do 'contraste, equilíbrio e peso', por meio de cinco experiências tato-gustativas e uma experiência tato-olfativa. As experiências tato-gustativas (Fig. 1) propõem como estímulo seis frutas distintas e quatro tipos de biscoito, sendo que cada uma emprega somente dois elementos da mesma categoria (fruta ou biscoito). Já as experiências tato-olfativas (Fig. 2) utilizam duas essências aromáticas contrastantes, aplicadas em chumaços de algodão. Importante mencionar que é concedida aos alunos a opção pela não ingestão dos estímulos gustativos, bem como pela não inalação dos estímulos olfativos, nos casos de intolerância ou alergia.

A primeira dupla de estímulo tato-gustativo é composta por um bago de uva e de mirtilo. A segunda, por uma maçã inteira e um gomo de tangerina. A terceira, por um tomate cereja e um morango. A quarta, por um biscoito de polvilho doce e um salgado. A quinta, por uma pipoca caramelizada e um biscoito de canjica. E a dupla de estímulo tato-olfativo compreende uma essência cítrica e uma doce.

Para receber cada dupla de estímulos tato-gustativo e tato-olfativo, solicita-se aos 32 estudantes posicionarem as duas mãos sobre a mesa de desenho, com as palmas voltadas para cima. Em seguida, os alunos manuseiam os estímulos de modo a perceber, inicialmente por meio do tato, as características semelhantes e distintas entre cada um: peso, tamanho, formato, textura, e temperatura. Na sequência, percebem as diferenças e as semelhanças entre os sabores e os aromas, ao degustá-los e inalá-los, respectivamente. Durante este processo, os estudantes são orientados a perceber as relações de contraste, equilíbrio e peso entre cada dupla de estímulos, bem como prestar atenção às imagens mentais (figurativas e/ou abstratas) evocadas a partir delas. E, por fim, são motivados a criar uma composição visual, com instrumentos e suportes de livre escolha.

Fig.1. Dos autores, Dinâmicas sensoriais: estímulos gustativos 2019.
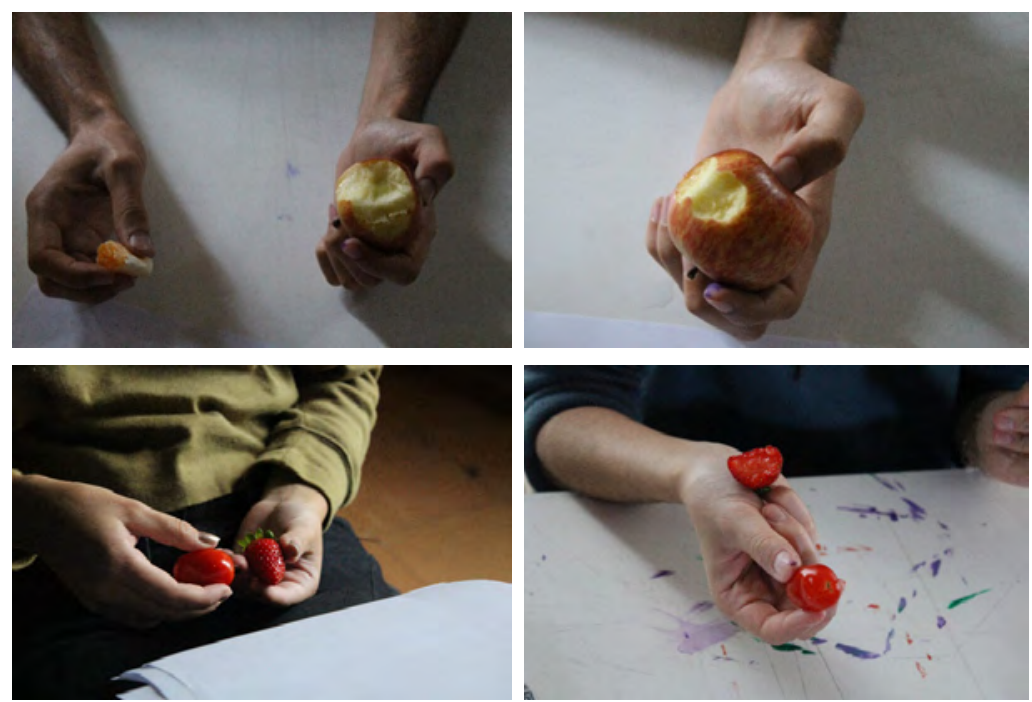

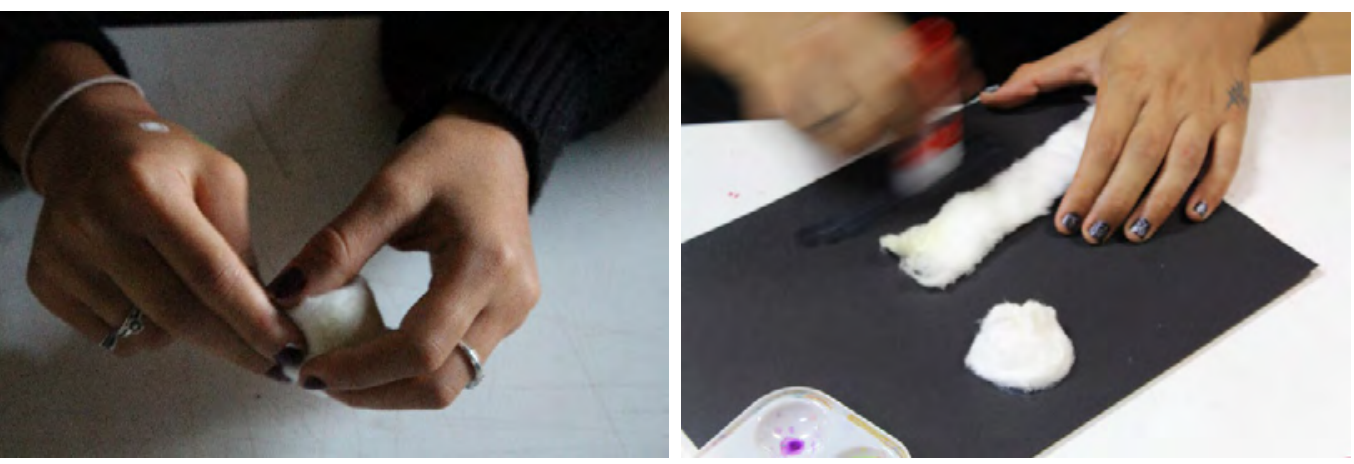

Fig. 2. Dos autores, Dinâmicas sensoriais: estímulos olfativos, 2019.

A seguir, discorreremos sobre os resultados compositivos obtidos a partir da sensibilização direta dos sistemas somatossensorial e sensório-motor dos estudantes, no âmbito do tema 'contraste, equilíbrio e peso'.

\subsection{Resultados Obtidos}

As dinâmicas sensoriais (cinco tato-gustativas e uma tato-olfativa), realizadas no contexto do tema 'contraste, equilíbrio e peso', totalizam 192 composições. Os resultados aqui apresentados são organizados em dois grupos: [1] suportes e instrumentos utilizados, o qual abrange as características presentes nos materiais escolhidos pelos alunos; e [2] elementos compositivos, o qual compreende as informações relacionadas aos elementos visuais e relacionais de contraste, equilíbrio e peso nas composições visuais. No caso dos resultados aqui descritos, importa mencionar que os estudantes optaram por não utilizar o tapa-olhos durante o desenvolvimento de suas composições visuais.

\section{[1] Suportes e Instrumentos}

No âmbito dos materiais escolhidos pelos estudantes, destacam-se dois resultados. O primeiro concerne ao [a] tipo, formato e cor do suporte, e o segundo ao [b] tipo de instrumento utilizado para realizar as composições visuais. Quanto ao resultado '[a]', mesmo com a livre escolha de materiais, todos os alunos optaram pelo uso do suporte papel, com gramaturas variadas. Importante notar que a maioria se apresenta no formato retangular, com variações de tamanho. Apenas 4 composições, dentre as 192, adotam formatos irregulares. Além disso, como é possível notar abaixo (Tabela 1), a escolha pelo suporte papel na cor branca se sobressai às demais. 
Tabela 1 - Dos autores. Tipo e cores dos suportes utilizados pelos estudantes para as composições visuais

Tabela 2 - Dos autores. Tipos de instrumento utilizados pelos estudantes para as composições visuais.

\begin{tabular}{|c|c|c|c|c|c|c|}
\hline Cor do papel & $\begin{array}{c}\text { Dinâmica } \\
1\end{array}$ & $\begin{array}{c}\text { Dinâmica } \\
2\end{array}$ & $\begin{array}{c}\text { Dinâmica } \\
3\end{array}$ & $\begin{array}{c}\text { Dinâmica } \\
4\end{array}$ & $\begin{array}{c}\text { Dinâmica } \\
5\end{array}$ & $\begin{array}{c}\text { Dinâmica } \\
6\end{array}$ \\
\hline Branco & 28 & 29 & 29 & 24 & 23 & 27 \\
\hline Pardo & 2 & 1 & 1 & 3 & 2 & 1 \\
\hline Azul & 1 & - & - & 3 & 3 & 1 \\
\hline Rosa & 1 & - & - & - & - & - \\
\hline Vermelho & - & 1 & - & - & - & 1 \\
\hline Amarelo & - & - & - & 1 & - & - \\
\hline Verde & - & - & 1 & 1 & 1 & - \\
\hline Preto & - & - & - & - & 2 & 2 \\
\hline Roxo & - & - & - & - & - & 1 \\
\hline
\end{tabular}

Com relação ao resultado '[b]', destaca-se o uso de instrumentos 'secos e rígidos', como canetas, lápis e gizes, acompanhado pelo uso combinado de instrumentos ('secos e rígidos' + 'aguados', como aquarela, tinta e nanquim) (Tabela 2).

\begin{tabular}{|c|c|c|c|c|c|c|}
\hline Instrumentos & $\begin{array}{c}\text { Dinâmica } \\
1\end{array}$ & $\begin{array}{c}\text { Dinamica } \\
2\end{array}$ & $\begin{array}{c}\text { Dinâmica } \\
3\end{array}$ & $\begin{array}{c}\text { Dinamica } \\
4\end{array}$ & $\begin{array}{c}\text { Dinâmica } \\
5\end{array}$ & $\begin{array}{c}\text { Dinâmica } \\
6\end{array}$ \\
\hline Apenas 'secos e rígidos' & 15 & 16 & 19 & 18 & 14 & 13 \\
\hline Apenas 'aguados' & 7 & 8 & 5 & 6 & 6 & 7 \\
\hline $\begin{array}{c}\text { Combinados ('secose } \\
\text { rígidos' + 'aguados') }\end{array}$ & 10 & 8 & 7 & 7 & 12 & 12 \\
\hline Total de composições & 32 & 31 & 31 & 32 & 32 & 34 \\
\hline
\end{tabular}

\section{[2] Elementos Compositivos}

No contexto dos [c] elementos visuais e relacionais de contraste, equilíbrio e peso (WANG, 1998), identifica-se que o contraste de cor se sobressai aos demais em todas as dinâmicas sensoriais (Tabela 3). 


\begin{tabular}{|c|c|c|c|c|c|c|}
\hline $\begin{array}{c}\text { Elementos visuais e } \\
\text { relacionais de contraste }\end{array}$ & $\begin{array}{c}\text { Dinâmica } \\
1\end{array}$ & $\begin{array}{c}\text { Dinâmica } \\
2\end{array}$ & $\begin{array}{c}\text { Dinâmica } \\
3\end{array}$ & $\begin{array}{c}\text { Dinâmica } \\
4\end{array}$ & $\begin{array}{c}\text { Dinâmica } \\
5\end{array}$ & $\begin{array}{c}\text { Dinâmica } \\
6\end{array}$ \\
\hline Cor & 24 & 30 & 28 & 29 & 31 & 28 \\
\hline Formato & 21 & 23 & 22 & 11 & 9 & 5 \\
\hline Tamanho & 21 & 23 & 20 & 8 & 13 & 8 \\
\hline Textura & 25 & 29 & 30 & 19 & 23 & 13 \\
\hline Direção & 25 & 19 & 18 & 9 & 12 & 10 \\
\hline Posição & 27 & 18 & 22 & 10 & 15 & 17 \\
\hline Espaço & 26 & 26 & 21 & 16 & 16 & 15 \\
\hline Gravidade & 23 & 22 & 20 & 10 & 11 & 9 \\
\hline Total de composições & 32 & 31 & 31 & 32 & 32 & 34 \\
\hline
\end{tabular}

Fig. 3. Dos autores,
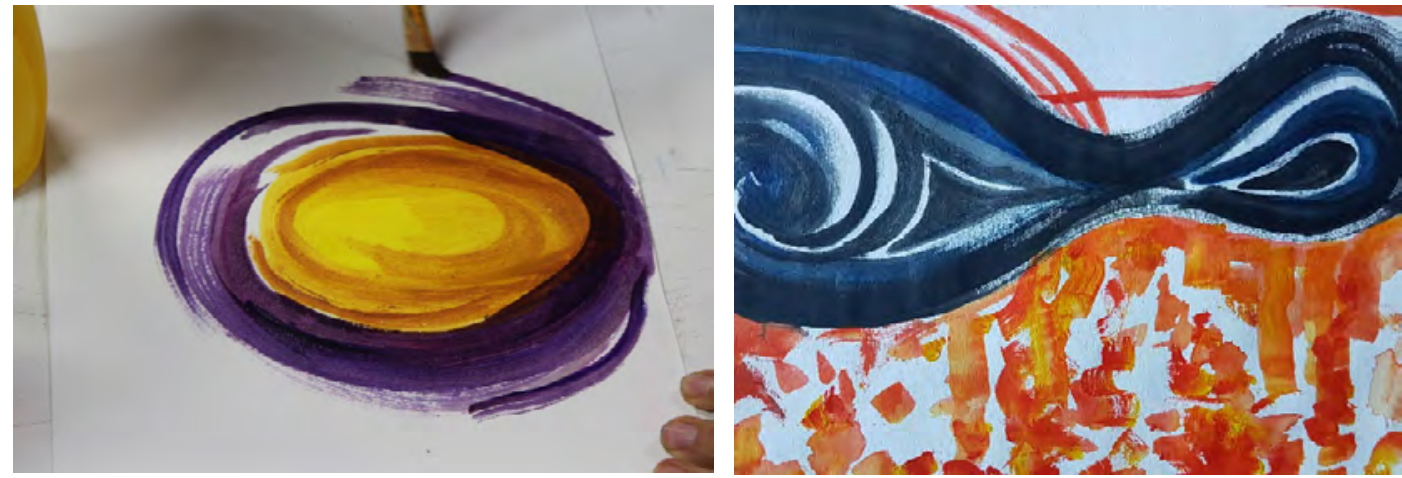

Além destes, outros três resultados mostram-se pertinentes ao também se destacarem nas composições desenvolvidas pelos estudantes, são eles: [e] o tipo de representação, se complexa ou literal; [f] o uso de palavras; e [g] a presença de imagens em duplicidade.

Com relação ao [e] tipo de representação visual (complexa ou literal) das imagens mentais formadas a partir dos estímulos somatossensoriais e sensório-motores (Fig. 4), a complexidade prevalece. Nota-se que poucos alunos optaram pela literalidade em suas composições. Alguns elementos literais apresentam-se combinados com elementos não-literais. Porém, o número de composições exclusivamente complexas mostra-se maior que as literais (Tabela 4).

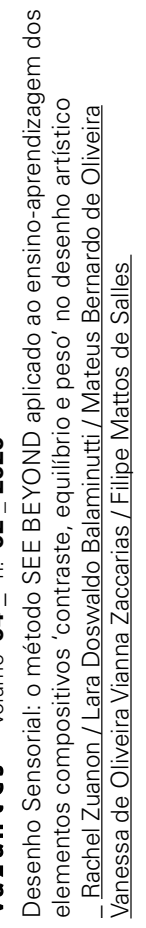




\begin{tabular}{|c|c|c|c|c|c|c|}
\hline Representação Visual & $\begin{array}{c}\text { Dinâmica } \\
I\end{array}$ & $\begin{array}{c}\text { Dinâmica } \\
2\end{array}$ & $\begin{array}{c}\text { Dinâmica } \\
3\end{array}$ & $\begin{array}{c}\text { Dinâmica } \\
4\end{array}$ & $\begin{array}{c}\text { Dinâmica } \\
5\end{array}$ & $\begin{array}{c}\text { Dinâmica } \\
6\end{array}$ \\
\hline Complexa & 19 & 12 & 16 & 17 & 16 & 21 \\
\hline Literal & 4 & 6 & 4 & 4 & 5 & 5 \\
\hline $\begin{array}{c}\text { Combinada } \\
\text { (Complexa } \\
\text { +Literal) }\end{array}$ & 9 & 14 & 11 & 10 & 12 & 8 \\
\hline \begin{tabular}{c} 
Total de composições \\
\hline
\end{tabular} & 32 & 31 & 31 & 32 & 32 & 34 \\
\hline
\end{tabular}

Tabela 4 - Dos autores.

Presença de elementos complexos e literais nas composições visuais realizadas pelos estudantes.

Fig. 4. Dos autores. Tipo de representação visual: [a] literal; [b] complexa; [c] elementos combinados, 2019 .

[a]

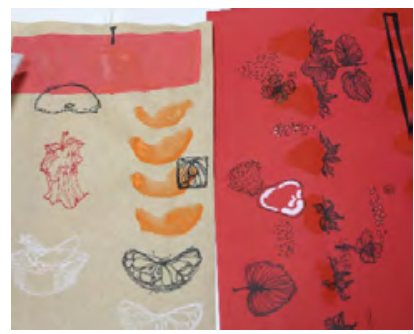

[b]

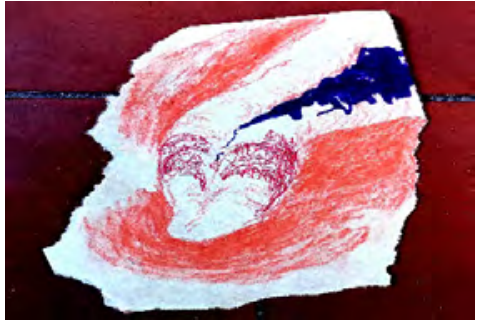

[c]

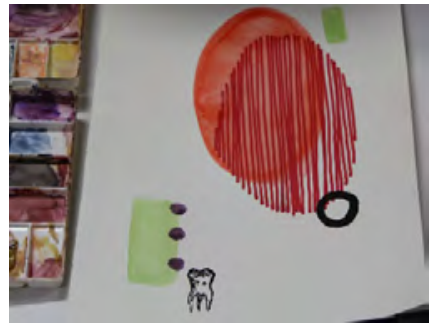

No que se refere ao [f] uso de palavras (Fig. 5), poucos estudantes utilizaram o recurso gráfico das palavras para expressar visualmente suas imagens mentais (Tabela 5).

\begin{tabular}{|c|c|c|c|c|c|c|}
\hline Elementos & $\begin{array}{c}\text { Dinâmica } \\
1\end{array}$ & $\begin{array}{c}\text { Dinâmica } \\
2\end{array}$ & $\begin{array}{c}\text { Dinâmica } \\
3\end{array}$ & $\begin{array}{c}\text { Dinâmica } \\
4\end{array}$ & $\begin{array}{c}\text { Dinâmica } \\
5\end{array}$ & $\begin{array}{c}\text { Dinâmica } \\
6\end{array}$ \\
\hline Palavras & 1 & 1 & 1 & 3 & 1 & 1 \\
\hline $\begin{array}{c}\text { Total de } \\
\text { composições }\end{array}$ & 32 & 31 & 31 & 32 & 32 & 34 \\
\hline
\end{tabular}

Tabela 5 - Dos autores. Presença de palavras nas composições visuais realizadas pelos estudantes.

Fig. 5. Dos autores. Elementos compositivos: palavras, 2019.
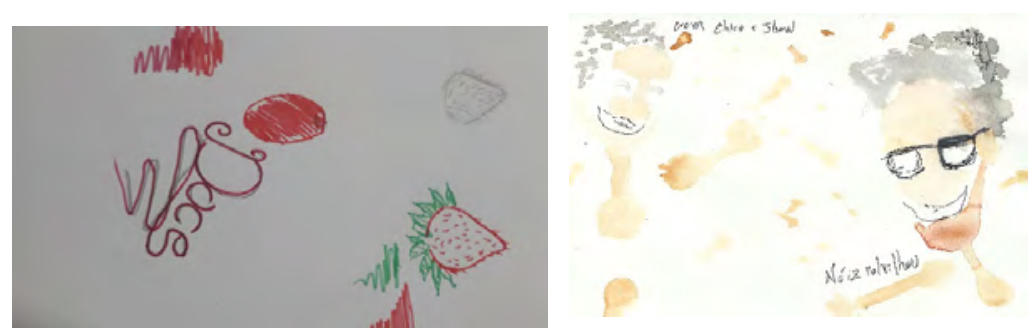

Por fim, a [g] presença de imagens em duplicidade destaca-se nas composições (Tabela 6). Tal duplicidade se mostra presente tanto nas representações visuais complexas, quanto literais (Fig. 6). 


\begin{tabular}{|c|c|c|c|c|c|c|}
\hline $\begin{array}{c}\text { Imagens em } \\
\text { duplicidade }\end{array}$ & $\begin{array}{c}\text { Dinâmica } \\
1\end{array}$ & $\begin{array}{c}\text { Dinâmica } \\
2\end{array}$ & $\begin{array}{c}\text { Dinâmica } \\
3\end{array}$ & $\begin{array}{c}\text { Dinâmica } \\
4\end{array}$ & $\begin{array}{c}\text { Dinâmica } \\
5\end{array}$ & $\begin{array}{c}\text { Dinâmica } \\
6\end{array}$ \\
\hline Complexas & 10 & 4 & 9 & 9 & 7 & 17 \\
\hline Literais & 6 & 9 & 6 & 6 & 8 & 6 \\
\hline Total de composições & 32 & 31 & 31 & 32 & 32 & 34 \\
\hline
\end{tabular}

Tabela 6 - Dos autores. Presença de imagens em duplicidade nas composições visuais realizadas pelos estudantes.

Fig. 6. Dos autores Imagens em duplicidade nas composições visuais realizadas pelos estudantes, 2019
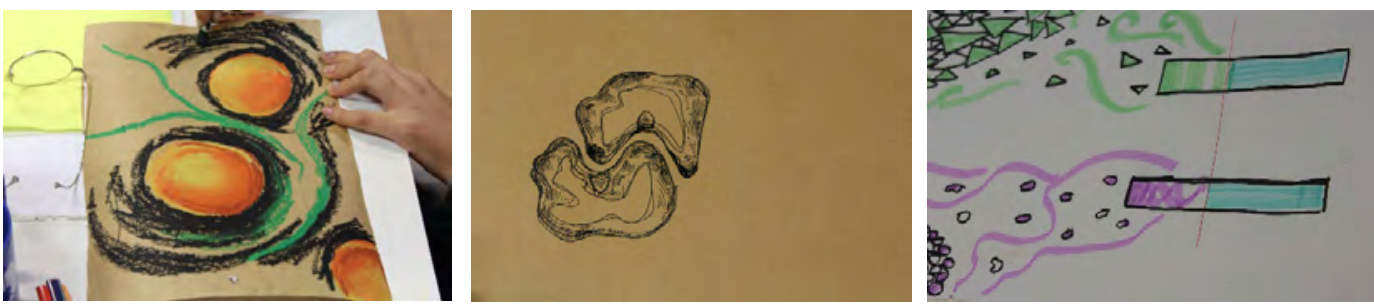

\subsection{Discussões}

Ao minimizar a ação do sentido da visão, os estímulos tatogustativos e tato-olfativos, propostos no âmbito da abordagem do Desenho Sensorial, protagonizam a sensibilização dos sistemas somatossensorial e sensório-motor dos estudantes, assim como a percepção dos tamanhos, formas, texturas, temperaturas, aromas, e sabores dos objetos entregues a estes. Ou seja, por meio desses estímulos, os alunos são instigados a assimilar as características de cada objeto, e a identificar as qualidades de 'contraste, equilíbrio e peso' ao manuseá-los. Ao longo deste processo, imagens mentais se formam no cérebro de cada aluno. Simultaneamente, suas memórias autobiográficas e afetivas são evocadas, e deflagram emoções e sentimentos correlacionados. Esse conjunto formado pelas imagens mentais, pelas memórias, e pelas emoções e sentimentos que esses estímulos suscitam, atuam diretamente sobre o próprio processo perceptivo dos objetos e das qualidades de 'contraste, equilíbrio e peso' e, consequentemente, sobre o processo criativo do aluno. Em outras palavras, a subjetividade que compõe este conjunto acompanha a capacidade de cada estudante em abstrair e se apropriar destes estímulos, para materializá-los em suas composições. Ao mesmo tempo, estes estímulos também fomentam e potencializam esta capacidade de abstração e de apropriação e, por conseguinte, de criação.

Neste sentido, as escolhas dos suportes e dos instrumentos, assim como dos elementos visuais e relacionais de contraste, equilíbrio e peso, empregados pelos estudantes em suas composições, refletem o encontro entre os [1] estímulos entregues aos alunos; [2] os estímulos internos produzidos pelos próprios corpos dos estudantes em resposta aos objetos recebidos nas palmas de suas mãos, e [3] em resposta aos estímulos externos providos pelo ambiente da sala de aula (temperatura, umidade, sons, iluminação natural, aromas, texturas dos mobiliários, entre outros); e [4] o conjunto de imagens mentais, memórias autobiográficas 
e afetivas, emoções e sentimentos, que marca a subjetividade e a individualidade de cada aluno. Em outras palavras, as decisões criativas que, em sua maioria, resultam no [i] suporte papel na cor branca, no formato retangular; nos [ii] instrumentos 'secos e rígidos'; no [iii] contraste de cor; na [iv] representação visual complexa; no [v] pouco uso do recurso gráfico das palavras; nas [vi] imagens em duplicidade; todas elas se coadunam aos estados do corpo alcançados pelos estudantes, no encontro supracitado.

Interessante notar que enquanto os elementos visuais e relacionais de contraste, equilíbrio e peso (formato, tamanho, textura, direção, posição, espaço e gravidade) mostram-se mais intensos nas dinâmicas sensoriais 1, 2 e 3, o contraste de cor se mantém presente e elevado em todas as dinâmicas. Tal resultado indica que os estímulos tato-gustativos e tato-olfativos empregados nestas dinâmicas despertaram na maioria dos estudantes o desejo pelo uso de cores em suas composições. Ou seja, independente do fato dos objetos/estímulos serem de naturezas distintas, a estimulação sensorial em si impulsiona o uso de cores.

Percebe-se também direta correlação entre os elementos visuais e relacionais de contraste, equilíbrio e peso (formato, tamanho, textura, direção, posição, espaço e gravidade) presentes nas composições realizadas pelos alunos e as qualidades de contraste, equilíbrio e peso observadas nos pares de objetos entregues aos estudantes. O que nos leva a compreender que tais qualidades são plenamente apreendidas pela percepção tato-gustativa e tato-olfativa, e independem da estimulação visual.

Ademais, especialmente importante ressaltar a preponderância da [v] representação visual complexa, bem como o [vi] pouco uso do recurso gráfico das palavras nas composições analisadas. Estes resultados externalizam e traduzem graficamente as memórias, as emoções e os sentimentos, evocados pelos estímulos como imagens na mente dos estudantes.

Cabe destacar, ainda, que a prevalência da [iv] representação visual complexa denota a significativa atuação dos referidos estímulos tato-gustativos e tato-olfativos, nos processos de abstração e de apropriação vivenciados pelos alunos. Ou seja, ao potencializar a abstração e a apropriação, estes estímulos corroboram ao distanciamento de representações visuais literais, e motivam a quebra de padrões/códigos pré-estabelecidos no repertório dos estudantes. Esta ruptura mostra-se crucial no processo de construção de uma expressividade autoral, extremamente cara à formação do artista contemporâneo.

Por outro lado, observa-se que a abstração e a apropriação, atingidas nas representações visuais das composições, não se estende ao suporte. Apesar dos sucessivos incentivos à exploração e à experimentação de materiais não convencionais, durante as dinâmicas sensoriais, a opção pelo [i] suporte papel na cor branca, no formato retangular, evidencia a dificuldade da maioria dos alunos em sair da própria 'zona de conforto' e romper com este limite.

Quanto às [vii] imagens em duplicidade, apesar dos estímulos sensoriais (tato-gustativos e tato-olfativos) serem distintos, suas características são percebidas e representadas em parte expressiva das composições como elementos quase idênticos, exceto 
pela diferenciação cromática. Isso nos leva a identificar estreita conexão entre as imagens em duplicidade e o fato destes estímulos sensoriais serem disponibilizados em pares aos estudantes.

\section{Considerações Finais}

Ao propor a estimulação direta dos sistemas somatossensorial e sensório-motor, a abordagem do Desenho Sensorial além de ampliar o potencial perceptivo, também expande oportunidades ao processo criativo dos estudantes. Esta expansão, ao mesmo tempo que incrementa o repertório sensorial dos alunos, favorece a ruptura de padrões/códigos cristalizados, seja nos seus desenhos ou nas suas outras formas de expressão artística e projetual.

Compreende-se como natural a resistência inicial dos alunos à essa abordagem. Especialmente pelo fato desta se distanciar sobremaneira da maioria das metodologias adotadas para o ensino-aprendizagem do desenho artístico. Contudo, gradualmente, os estudantes ganham confiança na proposta do Desenho Sensorial, principalmente ao identificarem as transformações positivas que este agrega ao seu processo criativo e, consequentemente, à qualidade expressiva das suas produções artísticas e projetuais.

Subsidiada pelo método SEE BEYOND, a abordagem do Desenho Sensorial se alinha a este em todos os seus princípios. Cabe aqui enfatizar as transversalidades do método. São elas que asseguram ao Desenho Sensorial a plasticidade metodológica capaz de adaptar suas estratégias de ensino às necessidades individuais e coletivas dos estudantes. Isso se mostra ainda mais relevante pelo fato das disciplinas ofertadas pela Universidade Estadual de Campinas (UNICAMP) receberem alunos dos seus distintos cursos de formação em nível superior.

Os resultados e as discussões realizadas no âmbito deste artigo, longe de totalizar as contribuições do Desenho Sensorial à formação de nível superior, privilegiam àquelas diretamente associadas às estimulações tato-gustativas e tato-olfativas, vinculadas ao tema 'contraste, equilíbrio e peso'. Os demais resultados e contribuições alcançados junto aos outros eixos temáticos trabalhados no âmbito da disciplina 'Desenho Artístico I', 'Desenho Artístico II' e 'Desenho Artístico III', ministradas ao longo do ano de 2019 no Instituto de Artes da UNICAMP, são objetos de publicações futuras.

\section{Referências}

ALMEIDA, R.D.: Cartografia e Infância. In: VI Colóquio de Cartografia para Crianças e II Fórum Latino-americano de Cartografia para Escolares. Juiz de Fora -MG. 2009. Disponível em:<http://www.scribd.com/doc/21198272/ Cartografia-e-infancia? secret password=1y7uc0bv6objyzc80osp $>$ Acesso em: 6 ago. 2020.

BALLESTERO-ALVAREZ, J.A.: Multissensorialidade no ensino de desenho a cegos. Dissertação de mestrado. USP, São Paulo (2003). Disponível em: <https://goo.gl/s4QJJr>. Acesso em 10 de ago. 2020.

BRANDÃO, A. dos S.; CALIATTO, S. G.: Contribuições da neuroeducação para a prática pedagógica. Revista Exitus, [S. I.], v. 9, n. 3, p. 521-547, 2019. DOI: 10.24065/2237-9460.2019v9n3ID926. Disponível em: http:// 
www.ufopa.edu.br/portaldeperiodicos/index.php/revistaexitus/article/ view/926. Acesso em: 10 set. 2020.

CARDEAL, M.: Ver com as mãos: a ilustração tátil em livros para crianças cegas. Dissertação (Mestrado em Artes Visuais) Centro de Artes. Universidade do Estado de Santa Catarina. Florianópolis, 2009.

CARTER, R.: O livro de ouro do cérebro. Ediouro, Rio de Janeiro (2003). COSENZA, R.M.: Guerra, L.B. Neurociência e educação: como o cérebro aprende. Artmed, Porto Alegre (2011).

DAMÁSIO, A.R.: O erro de Descartes: emoção, razão e o cérebro humano (The mistake of Descartes: emotion, reason and the human brain). Companhia das Letras, São Paulo (2012).

DAMÁSIO, A.R.: E o cérebro criou o homem. Companhia das Letras, São Paulo (2011)

DAMÁSIO, A.R.: Em busca de Espinosa: prazer e dor na ciência dos sentimentos. Companhia das Letras, São Paulo (2004).

DARRAS, B.: La modélisation sémiocognitive a l'épreuve des résultas des neurosciences. Le cas de la production des schémas graphiques. Recherches en Communication. n.19, p.175-197, 2003. Disponível em: $<$ http://sites.uclouvain.be/rec/index.php/rec/article/viewArticle/5251>. Acesso em: 6 de ago. 2020

DOIDGE, N.: O cérebro que se transforma. Como a neurociência pode curar as pessoas. Rio de Janeiro : Record, 2011.

FEUERSTEIN, R., FEUERSTEIN, R.S., FALIK, L.H.: Além da inteligência: aprendizagem mediada e a capacidade de mudança do cérebro. Vozes, Petrópolis, RJ (2014).

JULIASZ, P.C.S; ALMEIDA, R.D.: A representação espacial na Educação Infantil sob a ótica da teoria Sócio-cultural e das relações tempoespaço-corpo. Anais. XXIV Congresso Brasileiro de Cartografia, Aracaju, 2010. Disponível em: <http://arquivo.sepq.org.br//V-SIPEQ/Anais/artigos/13. pdf> Acesso em: 6 ago. 2020

LIMA JÚNIOR, G. C., ZUANON, R.: SEE BEYOND: Enhancement - Strategies in Teaching Learning as a Stimulus to Creativity in Fashion Design. Lecture Notes in Computer Science, vol. 10917, 2018a.

LIMA JÚNIOR, G. C.; ZUANON, R.: SEE BEYOND contributions to the project-based practice of sighted and visually impaired students in the context of higher education in Design. Disponível em: <https:// ppgdesign.anhembi.br/datjournal/index.php/dat/article/view/91> 2018b. Acesso em: 10 ago. 2020.

LIMA JÚNIOR, G.C.; ZUANON, R.: The foundation of the SEE BEYOND method: fashion design and neuroeducation applied to the teaching of the project methodology to students with congenital and acquired blindness. In: Streitz, N., Markopoulos, P. (eds.) DAPI 2017. LNCS, vol. 10291, pp. 528-546. Springer, Cham (2017).

LURIA, A.R.: A construção da mente (The making of mind). Ícone, São Paulo (1992).

MARTIN, J.H.: Neuroanatomia: texto e atlas [Neuro-Anatomy: Text and Atlas]. AMGH, Porto Alegre (2013).

MATURANA, H.R., Varela, F.J.: The Tree of Knowledge: The Biological Bases of Human Understanding. Palas Athena, São Paulo (2001).

MORA, F.: Neuroeducación, solo se puede aprender aquello que se ama Madrid. Alianza Editorial, (2013).

NICOLELIS, M.: Muito além de nosso eu: a nova neurociência que une cérebros e máquinas. Companhia das Letras, São Paulo (2011)

SACKS, O.: O olhar da mente. Companhia das Letras, São Paulo (2010).

TABACOW, L.S.: Contribuições da neurociência cognitiva para a formação de professores e pedagogos. Disponível em: <http://www.bibliotecadigital. puc-campinas.edu.br/tde_arquivos/3/TDE-

2006-06-30T115909Z-1178/Publico/Luiz\%20Tabacow.pdf>. Acesso em 12 ago. 2020.

TOKUHAMA-ESPINOSA, T.N.: The scientifically substantiated art of teaching: a study in the development of standards in the new academic field of neuroeducation (mind, brain and education science). Capella University (2008). Disponível em: <http://pqdtopen.proquest.com/doc/250881375. html?FMT=ABS> Acesso em 6 ago. 2020.

WONG, W.: Princípios de forma e desenho. São Paulo: Martins Fontes, 1998. 